\title{
Classical, Innovative and Unconventional Coastline Protection Methods
}

\author{
Henk Jan Verhagen \\ Coastal Engineering section, Delft University of Technology, the Netherlands
}

\begin{abstract}
The purpose of this paper is to give a state of the art overview of a number of recent developments in structures for shoreline protection. In other presentations the need of coastal protection structures is discussed, as well as solutions including "soft" technology like beach nourishment. See the papers of Dean and Pope.

Regarding loose armour new developments can be reported on the stability of rock in shallow water conditions. This topic will be elaborated in more detail in the presentation of Van Gent.
\end{abstract}

In case the required rock size becomes too large, usually concrete elements will be used. Many elements exist, a recent PIANC working group has identified 217 different elements, but most of them are applied only seldom. Recent developments in concrete elements are the Core-Loc (developed by the US Army Corps of Engineers) and the Xbloc (developed by Delta Marine Consultants in the Netherlands). Both blocks have specific advantages in making a stable slope protection; the drawback of such blocks is the complicated shape, which makes them more costly.

One of the advantages of block like Core-Loc and Xbloc is that they can be applied as a single layer. Recent research has shown that simple concrete cubes can also be applied in a single layer, but only that special attention has to be paid to the placing density as well to the rock size in the secondary layer.

Another development is the use of extreme heavy aggregates; by using magnetite specific densities up to $4000 \mathrm{~kg} / \mathrm{m}^{3}$ can be achieved. The main advantage of using heavier densities is that the weight of the individual block may reduce with a factor 5 . Consequently thinner layer are possible, and also lighter construction equipment can be used.

As an alternative for rock and concrete structures can also be build up by using geofabrics. In fact these are all kind of variations on the sandbag. Geotextile technology makes it possible nowadays to create geofabrics with all kind of required strengths and filter properties. Although there is still some debate on the durability of the geofabrics, in general it is accepted that by use of the material under water durability is not really a problem any more. Basically three types of geotextile structures are relevant in shoreline protection. Of course the classical sandbag is applied, but in large sizes. Open big bags of $1 \mathrm{~m}^{3}$ are often used for the creation of temporary dams, while closed bags are often placed as an underwater revetment or as a hidden protection only to become active in case of calamities. 
Other recent development in geofabrics is the application of Geocontainers and Geotubes. Geocontainers are huge bags (order of $250 \mathrm{~m}^{3}$ ), placed in situ using a split hopper barge. With Geocontainers relatively steep underwater structures can be constructed with mainly sand. Geotubes are long tubes, with a diameter in the order of $5 \mathrm{~m}$ and a length in the order of more than $100 \mathrm{~m}$. The Geotubes are filled in situ.

Both types are mainly applied in conditions where sand is available, but rock has to be imported, and in consequently rather expensive.

A last development to be discussed is the tendency to go to more simple constructions. Especially for small scale structures it is sometimes attractive not to make and advanced and precise design, but make it more simple over dimension some elements and accept damage. On the long run this may be a cheaper solution.

\section{New developments related to concrete armour units for breakwaters}

Traditionally rubble mound breakwaters are protected with armour consisting of large rock. Unfortunately for big waves, the required rock size becomes so large that it is often a problem to find these rocks. Therefore as an alternative already many years ago concrete elements have been used. Basically one may distinguish two tendencies in the development of concrete elements:

- Keep the element as simple as possible, to lower production and placing costs. The drawback is that the quantity of concrete is not minimal. This approach leads to the application of concrete cubes.

- Maximize the permeability and the internal friction. The drawback is that this leads to complicated shapes and costly production, but a low material quantity. This approach has lead to many units, like the Tetrapod, the Accropode, the Core-Loc and the Xbloc. All of these blocks are commercial developments and patented, although some patents are expired. Recently PIANC has published a catalogue with most of the concrete elements [PIANC-MarCom 2004]

With the Accropode a new development has started to make these elements fitted for placement in a single layer. This saves quite some material, and also reduces the total placing time. The drawback is that the shape becomes even more complicated, and that also the placement has to be done with care. Especially attention has to be paid to the placement of the first layer at the toe of the breakwater.

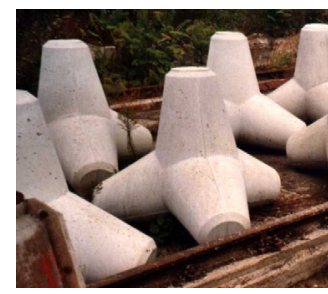

Tetrapod

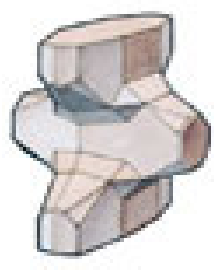

Accropode

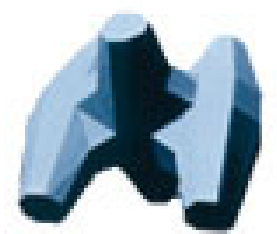

Core-Loc

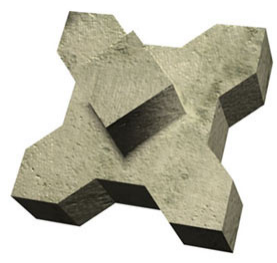

Xbloc

Various concrete elements for breakwaters

Some years ago in South Africa the Dolos, a very slender concrete element has been developed. This element was quite light, but extremely stable and has been applied for a number of breakwaters. Unfortunately, because of the slenderness of the element, there was an unexpected high risk of breaking of the legs. 
Based on the experiences with the Accropode and the Dolos in the previous decade a new block has been developed by the US Army Corps of Engineers, the Core-Loc. This block is very stable, and can be applied in a single layer [MELBY AND TURK, 1997]. Placement has to be done careful, according to strict guidance of engineers of Core-Loc.

Last year, Delta Marine Consultants, from the Netherlands, has presented a new block, the Xbloc, which is according to model tests, nearly as stable as the Core-Loc, and can also be applied in a single layer without problems. According to Delta Marine Consultants the advantages of this block are easier manufacturing and less strict placing regulations [REEDIJK ET.AL, 2003].

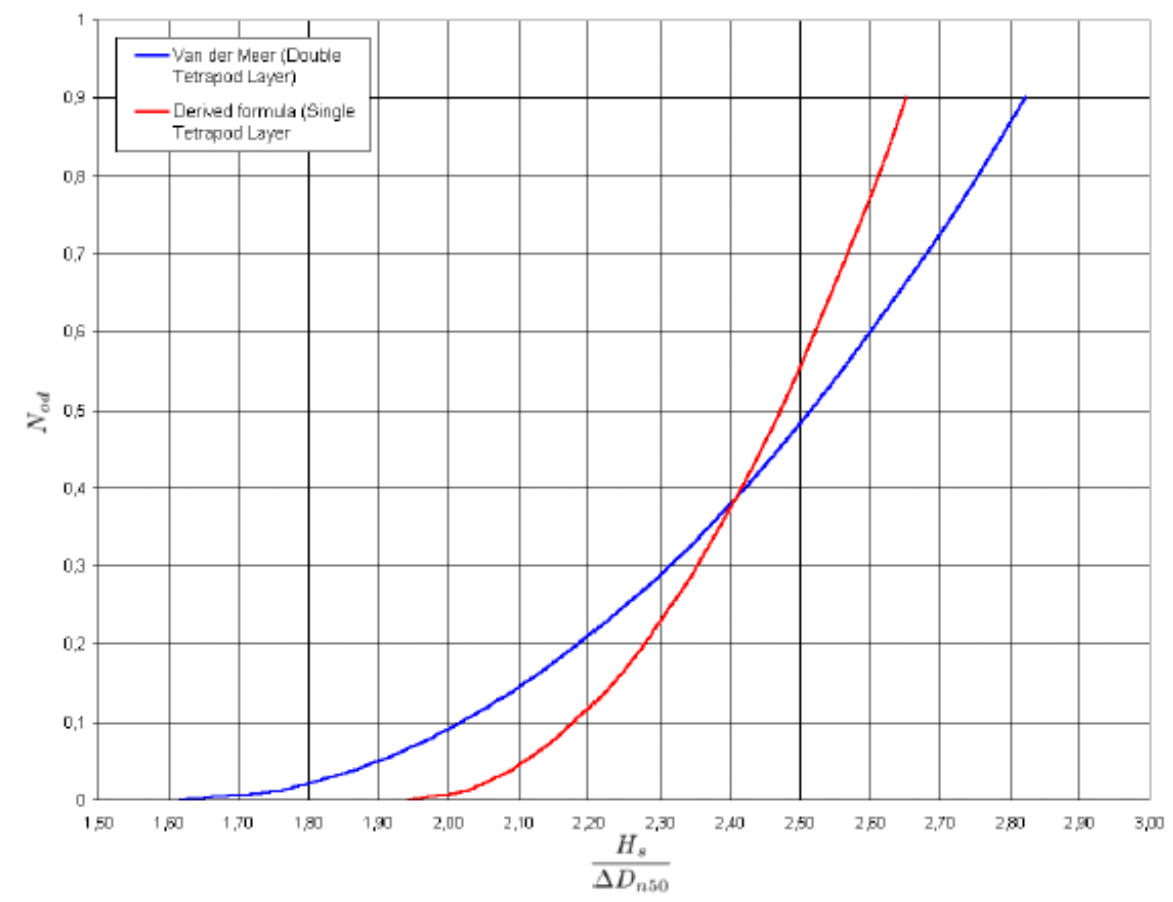

Stability of a single layer and a double layer of Tetrapods [DEJONG, 2003]

Although the Xbloc is smoother than the natural rock, the overtopping is less. This is mainly caused by the fact that the block has a higher void ratio than natural rock (recent research by KLABBERS [2004]).

Recent research in Delft has shown that also some older elements can be applied in a single layer configuration. Model tests with Tetrapods and with Cubes have shown that with both elements a stable construction can be achieved [BAGHELOE, 1998; VAN GENT ET.AL., 1999 and VANDENBOSCH ET.AL., 2002]. The packing density of the armour layer has be as such that $n_{v}<0.4$ ( $n_{v}$ is the void ratio). The placement density of the single layer has to be higher that in case of a double layer, and the secondary armour has to be slightly larger to prevent damage to the secondary layer.

In his research DEJoNG [2003] found that he damage to the secondary layer in case of a void ratio in the armour in the order of 0.3 was not caused by washing out of the material, but mainly because of sliding and displacement. Sliding and displacement did not occur. The experiments demonstrated that the erosion of the secondary layer is a function of the incident wave height rather than the armour layer packing density of the 
wave steepness. The general conclusion was that with a sufficient packing density of $n_{v}$ $<0.4$ and a normal designed secondary layer, the construction is stable, but that a somewhat different stability curve has to be used (see figure); the erosion in the secondary layer will never be more than three times the $D_{n 50}$ of the secondary layer.

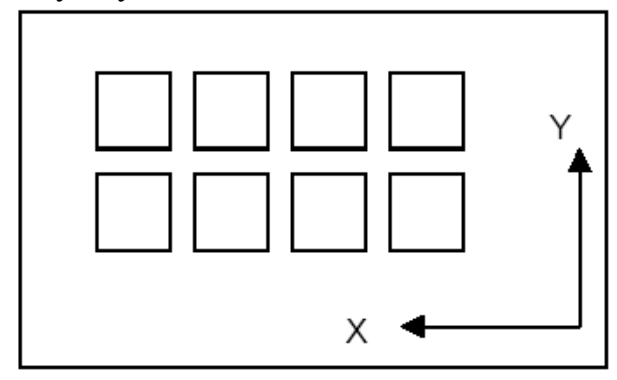

optie 1

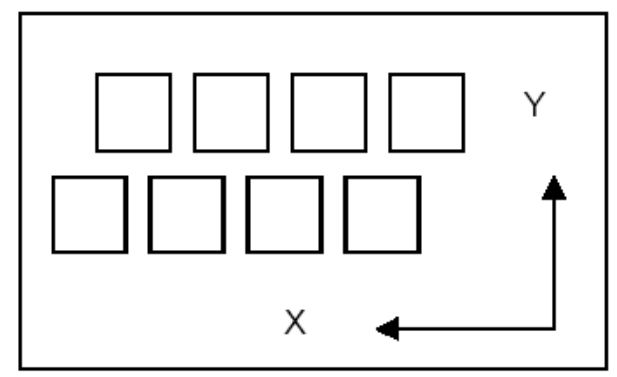

optie 3

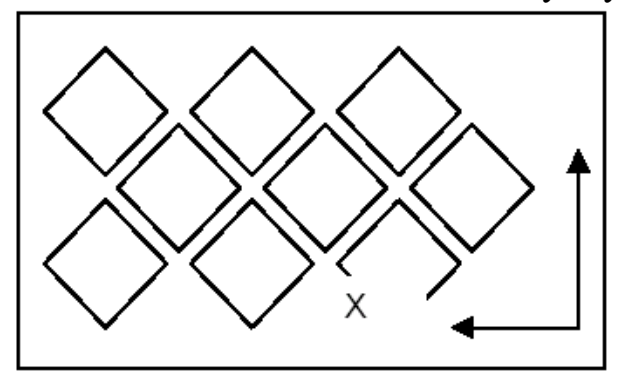

optie 2

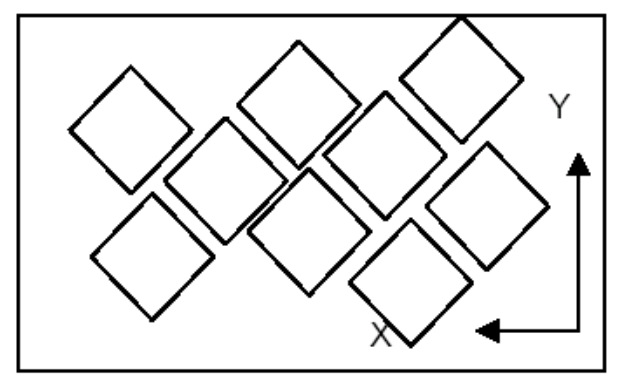

optie 4

Dumping options for cubes on a slope [VERHAGEN ET.AL, 2002]

Both for cubes as well as for Tetrapods the required placement density can be achieved by individual placing with cranes. Normally Cubes are dumped from a position around the waterline (this saves much time); it was found that the required placement density can be achieved also by dumping, provided the water depth is not more than approximately five times the block size. Also it was found that dumping in diagonal lines gives a much higher placing accuracy than dumping in parallel lines. Option 2 (see figure) gives the best results [VERHAGEN ET.AL., 2002]. This implies that dumping from a sidedumping barge is usually not a good option.
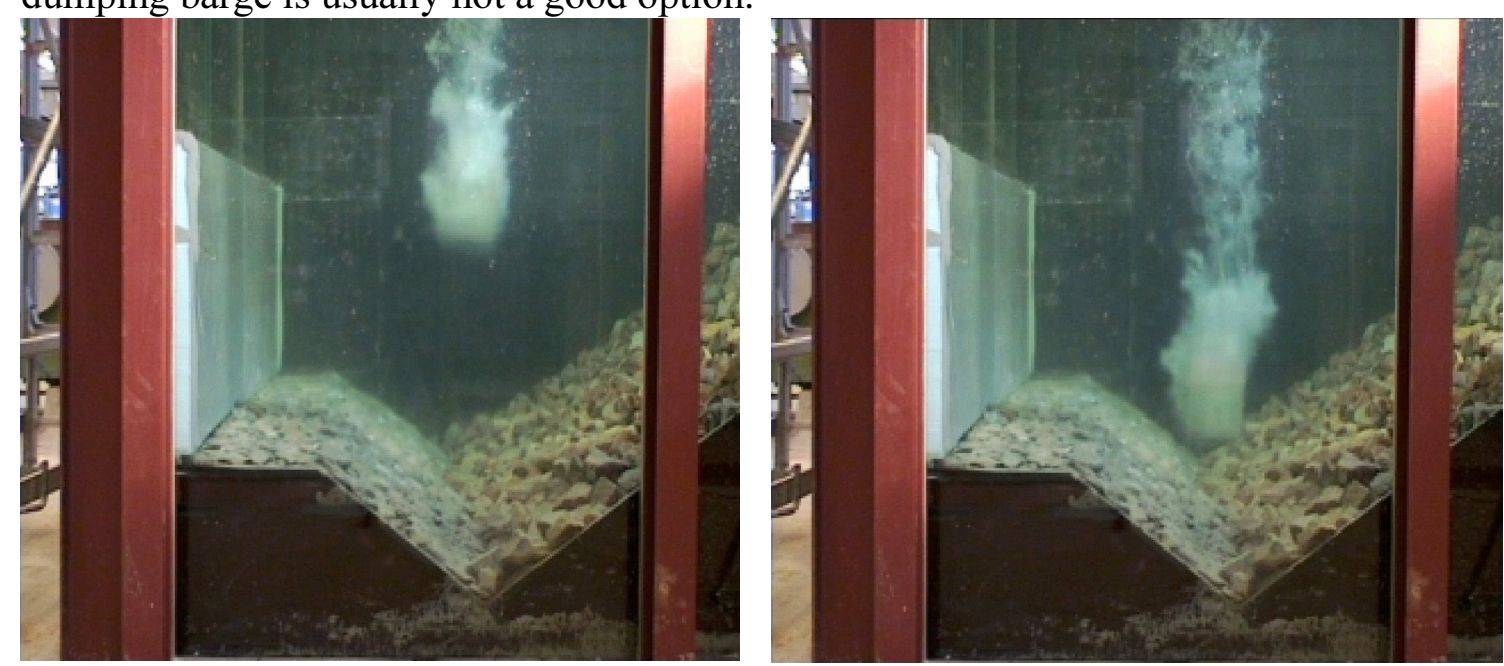

Dropping of a block in the laboratory [VERHAGEN ET.AL., 2002]. 
During the initial tests it was also clear that when the blocks were dropped from above the waterline, quite some air was enclosed. Blocks with much enclosed air did deviate less from the vertical path than blocks without air. So this gave the impression that dropping from above water would possibly result in more accurate dropping than in case the blocks were just dipped into the water. See figure. In addition, the rotation of the blocks was investigated in these initial tests. The conclusion was that all blocks did tilt somewhat, but that they did not really started to rotate.

\section{The use of heavy aggregates}

Nearly all stability equations for armour units use as stability number the parameter $(H / \Delta D)$. Because the density of the material is included in this parameter, it implies that an increase of density will also increase the stability. In the past this stability number had been validated for variations of density of a range between 2400 and $2800 \mathrm{~kg} / \mathrm{m}^{3}$. However, it is also possible to use extremely heavy aggregates, and to produce concrete with a density in the order of $4000 \mathrm{~kg} / \mathrm{m}^{3}$. Because it was not clear on beforehand that the stability relations are still valid for these values, some tests with extra heavy cubes have been done [TRIEMSTRA, 2000, 2001]. The advantages are not only that the same stability can be achieved with a much smaller block, but also with a lighter block. This seems somewhat contradictory but can be explained easily. Because the density is 1.6 times larger, the blocks can be 1.6 times smaller, which means that the volume is $1.6^{3}=$ 4 times smaller. And this means that that the weight per block is $4 / 1.6=2.5$ times less.

The result is that, although the material cost per $\mathrm{kg}$ is higher (because of the costly aggregate), the total concrete cost may be lower. But there are more additional benefits. Because the blocks are lighter, the cranes can be lighter too. Also the spread of the crane can be less. In this way a considerable saving can be achieved.

Example: A simple breakwater in $10 \mathrm{~m}$ waterdepth will require an Xbloc of approx. 6 tons. Assume the breakwater is $5 \mathrm{~m}$ above water level; then the total height is $15 \mathrm{~m}$ and the width of the slope $22.5 \mathrm{~m}$. With heavy aggregates only 2.5 tons is needed. For placing the 6 tons block over a distance of $22.5 \mathrm{~m}$ a 120 tons crane is needed. For placing 2.5 tons blocks on the same slope only a 40 tons crane is needed. The normprice of such a crane is only one third of the price of a 100 tons crane. Additional benefits are the smaller storage yard for the blocks, the easier transport, etc.

\section{Overtopping of breakwaters}

A long-term research programme on overtopping of sloping structures has resulted recently in a new set of guidelines for run-up and overtopping (VAN DER MEER, 2002). The formula has the overall shape of:

$$
Q^{*}=a \sqrt{\frac{\tan \alpha}{H / L}} \cdot \exp \left(b R^{*}\right)
$$

In which $\mathrm{Q}^{*}$ and $\mathrm{R}^{*}$ are the dimensionless overtopping, respectively the dimensionless crest height. The slope of the structure is given by $\alpha$, wave height and wave length are $\mathrm{H}$ and L. Additionally a number of coefficients are added to the equation to take into consideration effect of slope roughness, a berm, etc. 
Concrete breakwater elements are very permeable. This implies that overtopping is not only reduced by friction, but also because water flows into the structure. Both effects are usually taken into account in one single parameter, the roughness coefficient $\gamma_{\mathrm{f}}$. Consequently the value of this coefficient for artificial armour, like the Xbloc can be lower than for rock, although the slope looks much smoother. Recent tests for an Xbloc slope showed that the value of $\gamma_{\mathrm{f}}$ can be as low as 0.3 .

The fact that the foreshore is usually quite shallow is not directly taken into account in this equation. Investigations by VAN GENT [2001] have shown that for gentle, shallow foreshores the effect can be taken into consideration by not using the peak period in the equation, but by using the $\mathrm{T}_{\mathrm{m}-1,0}$.

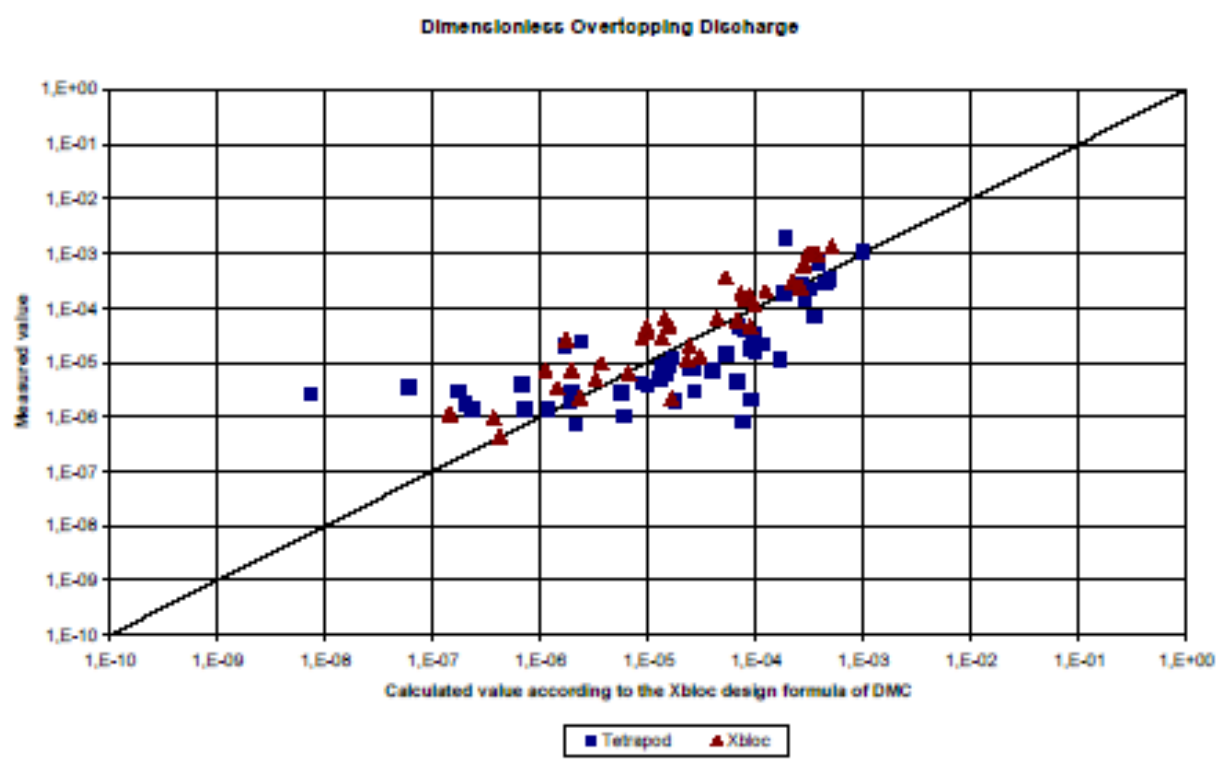

Dimensionless overtopping according to VanDerMeer and Klabbers equation for Tetrapods and Xbloc [CUI, 2004] 
As an alternative, KLABBERS ET.AL. [2003] has suggested not to use the Iribarren number $[\operatorname{Ir}=\tan \alpha / \sqrt{ }(H / L)]$ as basis for overtopping equations, but the Ursell number $[U$ $\left.=(H / d) /(d / L)^{2}\right]$. Especially for concrete breakwater units, this leads to a more accurate prediction of the overtopping. Their equation is:

$Q^{*}=a U \cdot \exp \left(b R^{*}\right)$

The fitted values for $a$ and $b$ are 0.01 and -3.58 . In this equation the local wavelength at the toe of the structure should be used.

From the above figures follows that especially for the Xbloc the formula of Klabbers et. al. gives better results, but it can be seen that also in case of a Tetrapod slope, the results of this equation not worse than the Van der Meer formula. One should realise that in the formula of KLABBERS ET.AL. the slope of the structure is not included as a parameter. This effect has not been investigated, because slopes with concrete breakwater elements are usually built up with a fixed slope of 1:11/2.

\section{The use of Geofabrics}

Geofabrics are used in many varieties in coastal protection. An important function of geofabrics is that they have filter properties, and may replace granular filters to prevent the washing out of fine particles. An other important function of geofabrics is that they can be used to construct containers for cheap aggregates, like sand, and in this way form large units to withstand the erosive forces of currents and waves. In this way, packed sand can become a substitute for rock and concrete elements. Three types of applications will be discussed in this paper.
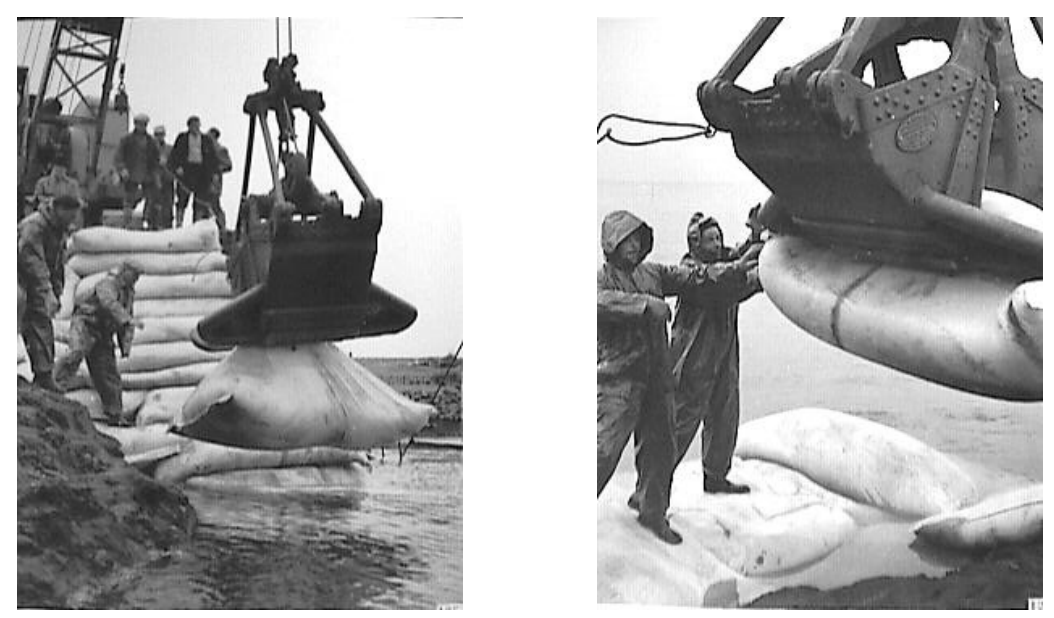

Nylon bags used for the closure of the Pluimpot, November 1957 (photo Cas Oorthuys, rvd)

\section{Large geotextile bags}

The use of simple sandbags is already quite old. For centuries the sandbag is used to combat flooding. However, as long as the sandbags have to be handled by hand, the size has to be limited. Sandbags should not weigh more than $50 \mathrm{~kg}$; otherwise accurate placing by hand is impossible (additionally European Labour Regulations limit the maximum weight of a bag to be handled by a single person to $25 \mathrm{~kg}$. A $50 \mathrm{~kg}$ bag may only be handled by two persons). But by using machines larger bags can be used. 
Already in 1957 tests with large nylon bags have been carried out during the closure of the Pluimpot estuary in the Netherlands. However, in subsequent years these bags have not been used frequently because of the high cost of the material in that time.

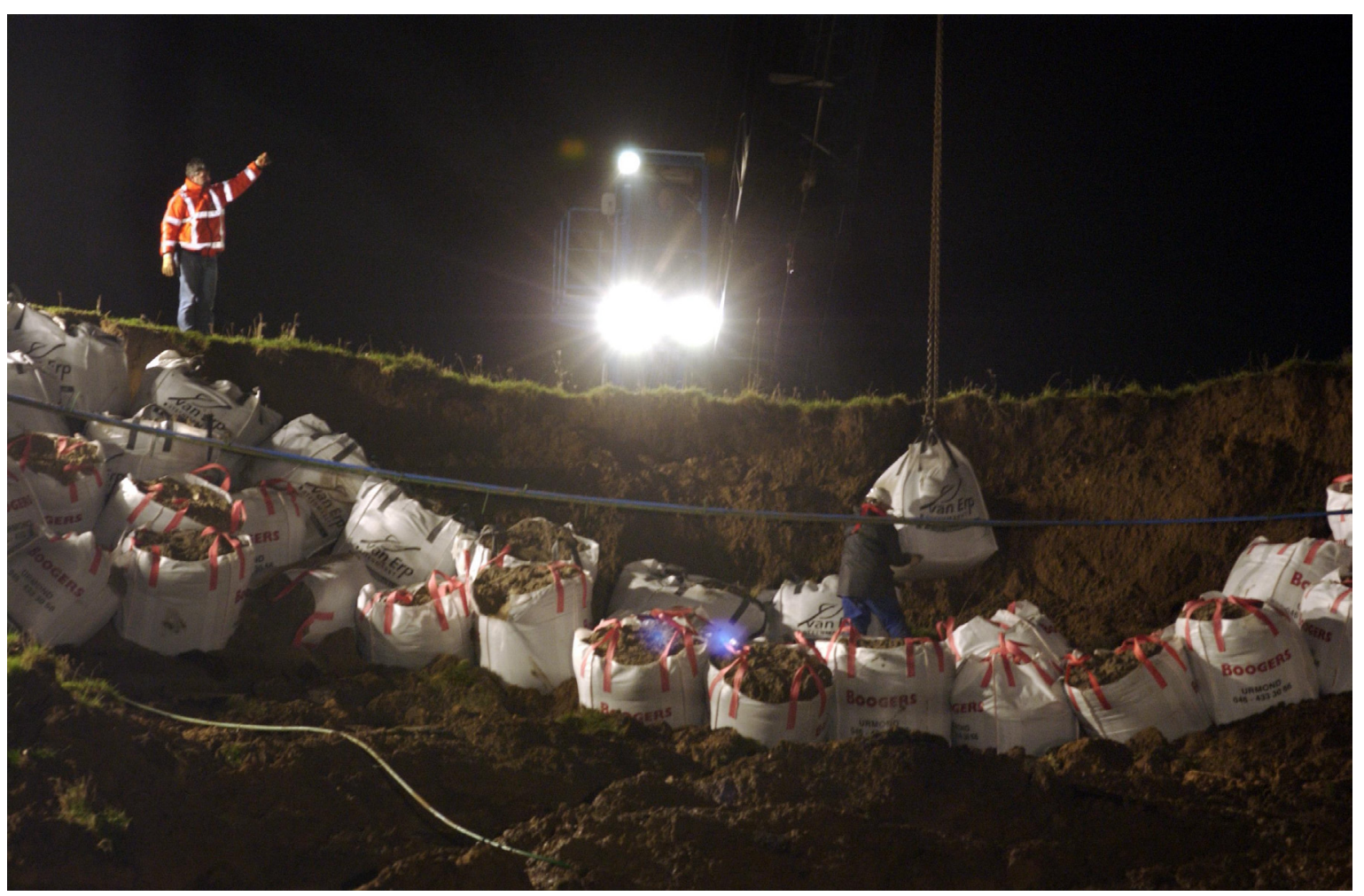

Emergency works at a dike breach in the Julianakanaal in the Netherlands, January 2004 (photo Michiel Wijnbergh/Hollandse Hoogte)

At this moment bags with a size of $1 \mathrm{~m}^{3}$ are quite standard for transport and storage of bulk material in industry. These bags can also be used easily for emergency dikes; during the river floods in recent years these bags have been applied often. For waterboards it is an attractive option, because the bags are very cheap (they usually are bought second hand), ample available on the market, and easy to fill and handle with forklifts or cranes.

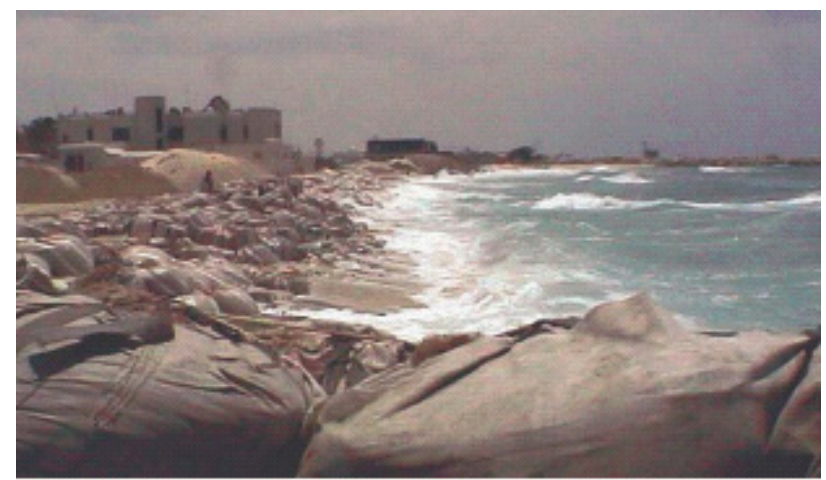

Deteriorating sandbags in Dubai, visual problems for local authorities [WEERAKOON ET.AL, 2003]

For permanent structures these types of bags are not often used. However, custom-made bags using strong non-woven material are used also for more permanent structures. At this moment such bags are also marketed as Soft Rock (trademark of Naue Fasertechik, 
Germany). For permanent structures it is very important to guarantee a sufficient degree of filling, otherwise the bas are not stable under wave conditions.

Usually the bags are applied as a "hidden protection". In fact they form a layer of coastal protection, which only becomes effective during storms, in order to prevent excessive cross-shore erosion. In case of erosion due to a gradient in longshore transport longshore protections are not effective. However, bags can be applied also to construct a groyne, although in most cases preference is given then to Geotubes.

As mentioned, longshore constructions are often executed as "hidden protection". In this way it is prevented that UV-radiation is damaging the geotextiles, but also the geotextiles become less vulnerable to vandalism. Although damage by vandalism can be repaired (see also below when the Geotubes are discussed), this is costly and requires quite some management effort.

Because the bags usually are not fully stable, they will deform. A slight deformation is not a problem from a strength point of view, but gives a negative visual impact. Usually this is not acceptable for beaches with a tourist function.

One should realise that a longshore hidden protection can be executed easily, but it is not possible to construct groynes with sandbags as a hidden construction. They only way to hide sandbags in a groyne is cover them with rock. However, in most cases this is economically not attractive.

\section{Geocontainers}

Geocontainers are relatively new engineering systems. Nicolon has developed the system and also copyrighted the name Geocontainer (NICOLON, 1988). Geocontainers are in fact large bags, filled in the hopper of a split barge and dumped by that barge on a selected position. Geocontainers has been applied at several places in recent years, mainly as fill units, shore protection and as breakwaters. The application depth is up to 30 meters. An overview of Geocontainer technology is given by PILARCZYK [2000].

The standard basic material of Geocontainers is the high grade Geolon PP with tensile strengths in both length and cross directions of 80- 100 and $200 \mathrm{kN} / \mathrm{m}$. Geocontainers are always custom build to fit the hold of the split-bottom barge to be used; hold capacities vary from $200 \mathrm{~m}^{3}$ to $300 \mathrm{~m}^{3}$.
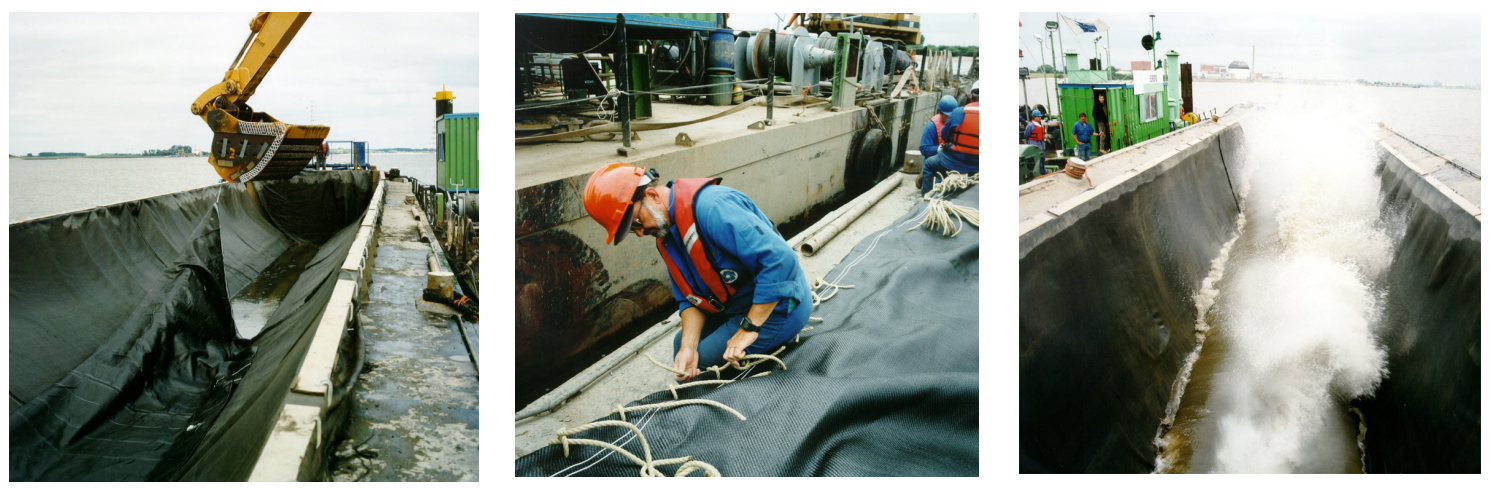

Placing a Geocontainer (Photos Rijkswaterstaat, DWW)

The procedure is that the empty Geocontainer is placed in the hold of the split barge, the container is filled with an appropriate material, and the container is closed by sewing. 
Then the barge sails to the right position and the container is dumped to the right position.

The advantages of the system are:

- containers can be filled with locally available soil; this can be from a land source or from near dredging activities;

- containers can be placed relatively accurately regardless the weather conditions, current velocities, tides and waterdepths;

- contained material is not subject to erosion during or after placement;

- containers can provide a relatively quick system build-up.

This implies that Geocontainers will mainly be applied in situations where sand is abundantly available and rock is costly; where gently construction slopes have to be avoided and where erosion by currents and waves may be a problem.

The main design considerations include sufficient strength of the geotextile and appropriate filling. Because Geocontainers are applied under water, the effect of UV and vandalism are usually negligible.

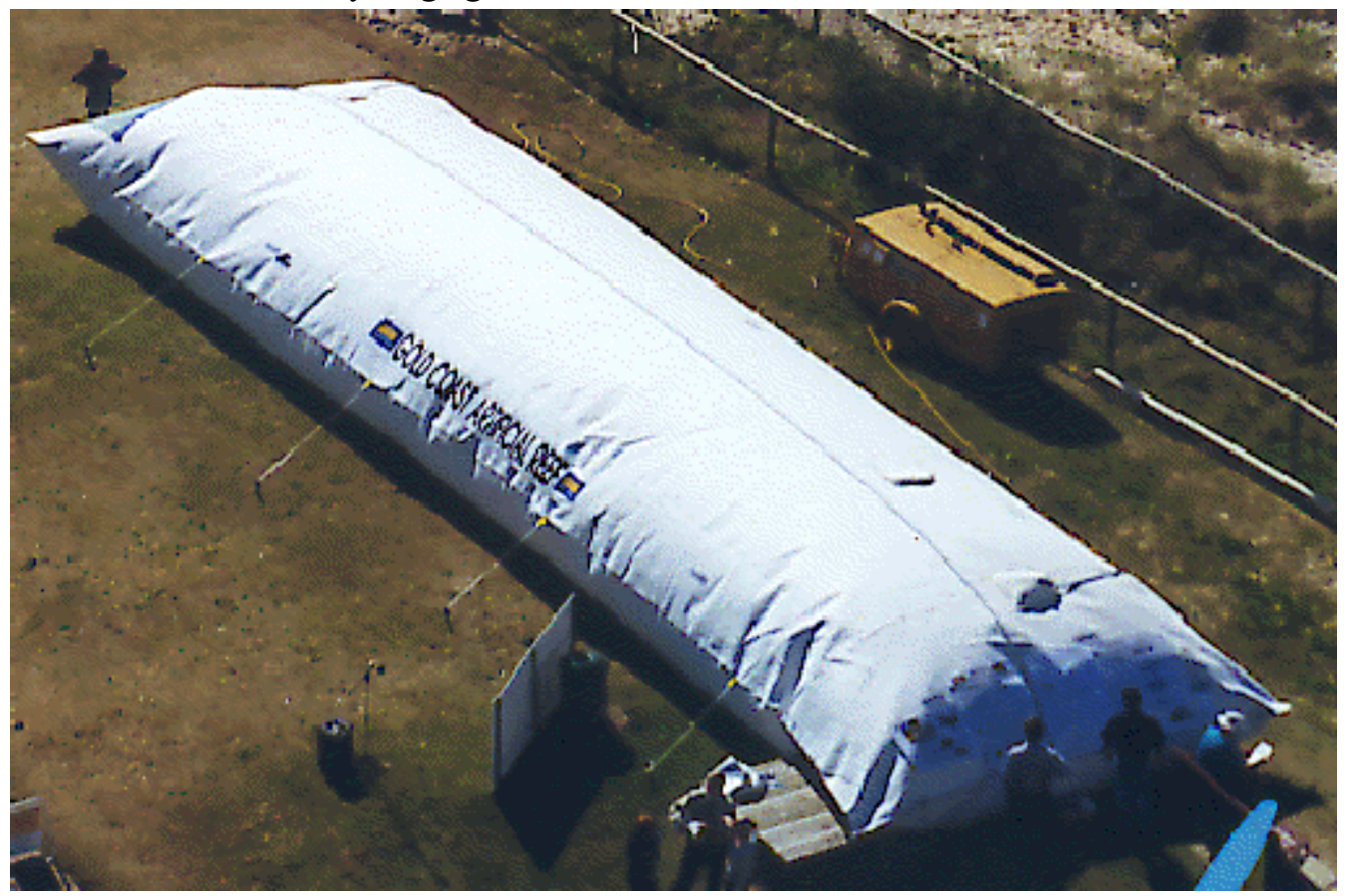

Demo Geocontainer on a beach, Goldcoast, Australia

A Geocontainer will always contain a certain amount of air in the pores of the sand; the behaviour of this air determines largely the behaviour of the Geocontainer during sinking. Recently [DE GROOT ET.AL.,2003] detailed research has been done on the most relevant problems:

- the positioning of the Geocontainer during sinking;

- the geotechnical stability of the Geocontainers;

- the overload on the Geocontainer during dumping;

The tests resulted in the conclusions that in waterdepths of approximately 20 meters is was no problem to build up a 1:2 slope in still water and a 1:3 slope under conditions 
with waves and currents. The basis for this test was a $300 \mathrm{~m}^{3}$ container. Placing the first container is the most difficult operation; the following containers can be placed more easily. In shallow water (less than $10 \mathrm{~m}$ ) the placing accuracy is much better; slopes of 1:1.5 may be achieved.

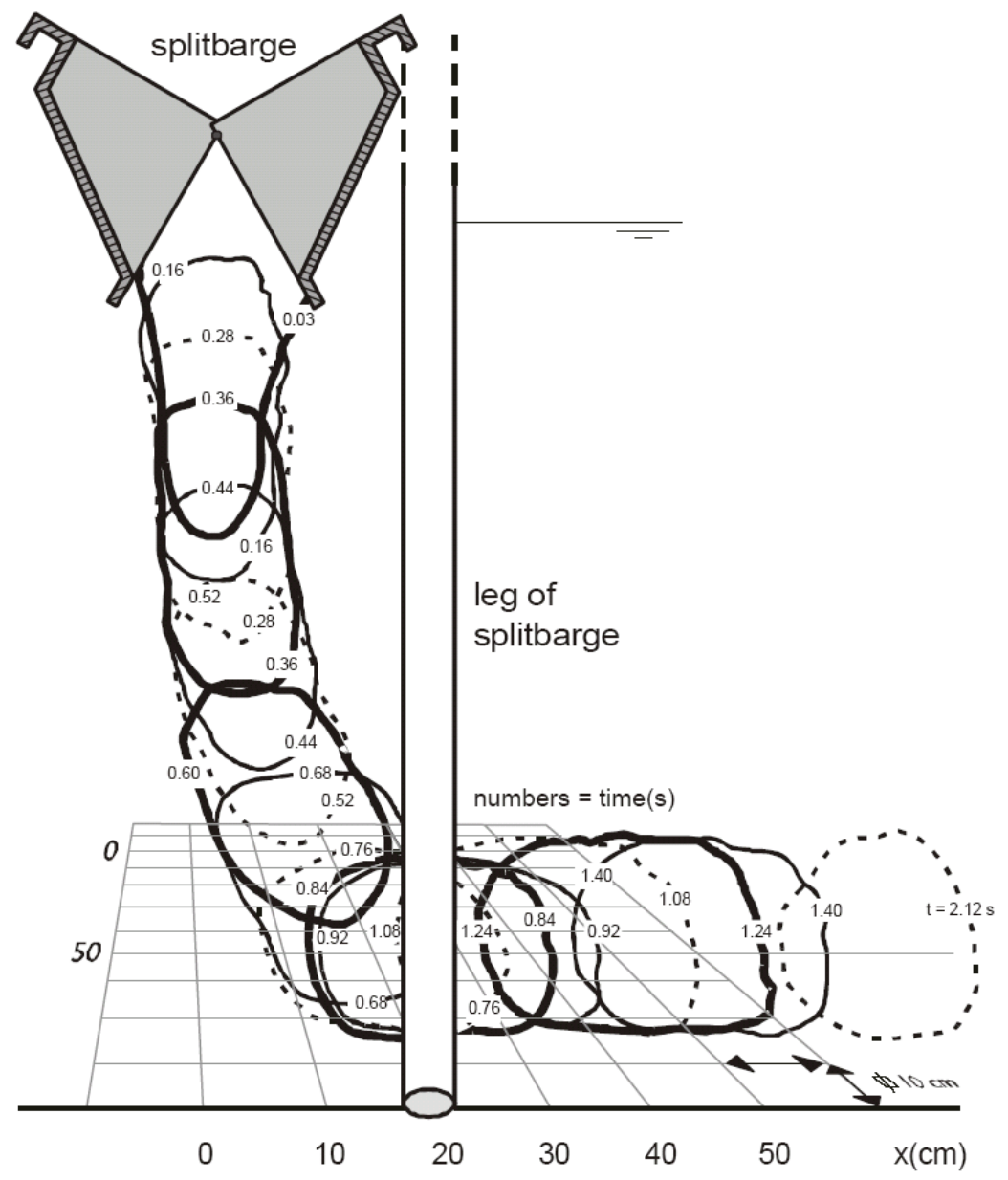

Falling pattern of a Geocontainer [DE GROOT ET.AL, 2003]

Regarding the strength it was found that a nominal tensile strength of $120 \mathrm{kN} / \mathrm{m}$ for waterdepth up to $15 \mathrm{~m}$ did not cause any problems provided the sand had a low content of fines (less then $20 \%$ particles smaller than $63 \mu \mathrm{m}$. It is not expected that this conclusion will be changed for larger waterdepths. Only for extremely shallow water the falling energy reduces considerably, which implies that that a tensile strength of 120 $\mathrm{kN} / \mathrm{m}$ should be applied for all Geocontainers. Also it was found that using dry sand decreases the falling velocity and consequently the impact energy.

The geotechnical stability gave steeper critical slopes that the slopes which could be achieved by dumping; so geotechnical stability is not a criterion.

Geocontainers under wave attack are stable for values of $H_{s} / \Delta d$ up to 1 . In this equation $\mathrm{d}$ is the height of the container after dumping. Practically it means that Geocontainers are stable up to waves of $3 \mathrm{~m}$. The critical velocity for a pile of Geocontainers is given by $u / \sqrt{ } g \Delta d<0.5$ to 1 . Liquefaction is no problem when the Geocontainer is filled with sand without fines (less than $20 \%$ silt fraction). 


\section{Geotubes}

Geotubes are long woven polypropylene tubes; the name Geotube is a registered trademark from Nicolon, the Netherlands. The main difference with the Geocontainer is that the Geocontainer is filled before placement, while the Geotube is filled in place. This allows a longer structure. Geotubes are mainly used as core elements for dams and dikes, as groynes and as longshore protection. Recently in the Netherlands Geotubes are applied as core elements for guide dams near a lock and an aqueduct [SPELT, 2001]. Experience in Dubai [WEERAKOON ET.AL.2003] with unprotected Geotubes showed that with a qualified contractor the construction is no problem at all, but that because of wave action, some damage may occur to the tubes during minor storms. This damage causes leakage of the tubes, and sand will flow out of the tube. The final result is some slumping of the tubes, and consequently the tube is not able to fulfil its function any more in a proper way (in this case the function of the tube was to protect an artificial beach).

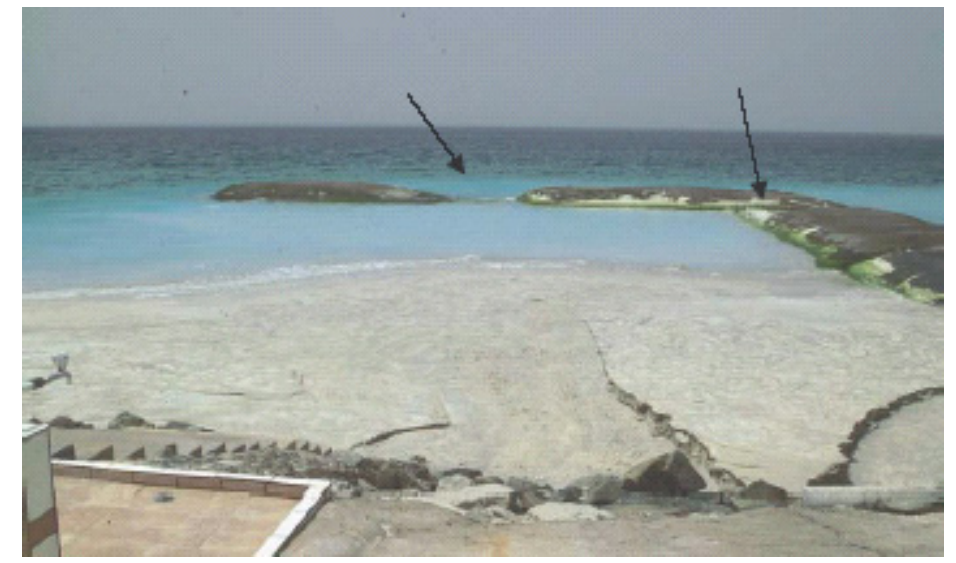

Slumping of a Geotube after a small storm in Dubai [WEERAKOON ET.AL, 2003]

The exact cause of the damage is not fully understood. Probably it is a combination of rocking of the structure itself, causing a movement of sand inside the tube, in combination with some scouring under the tube. This may cause extreme tensions in the geotextile, leading to ruptures.

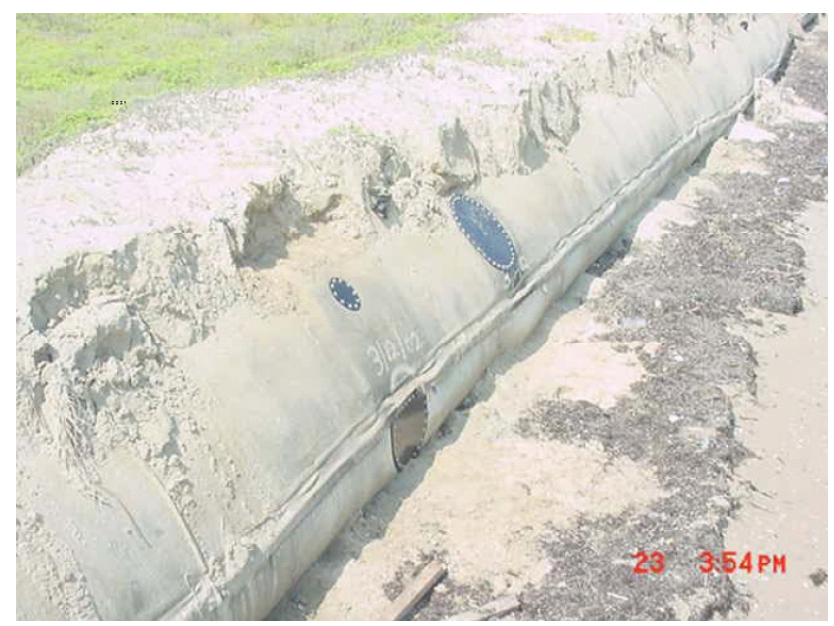

HDPE repair plates for a Geotube [HEILMAN \& HAUSKE, 2003] 
Geotubes, like other geotextile structures, are vulnerable to damage, both natural and man-induced. It is essential that damage be repaired as soon as possible. Recently a method has been developed by HEILMAN AND HAUSKE [2003] to repair such structures, using HDPE repair plates. Although this works very well from a technical point, it requires a good management of the structure. The structure has to be monitored very regularly, and repair has to be done immediately after ascertaining the damage.

\section{Simple construction}

The total costs (sum of construction costs and capitalized maintenance costs) of simple coastal structures, like groynes, can be decreased significantly by simplifying the structure [CROSSMAN ET AL., 2003]. Fewer layers and less prepared foundations make construction operations easier and quicker. Reducing the depth of excavation, limiting geotextiles and reducing the number of rock gradings can achieve considerable savings. Also the volume of rock used in structures can be reduced as a result of less extensive foundations and improved understanding of performance requirements. Substitution of rock by alternatives (particularly waste) materials may also lead to savings.
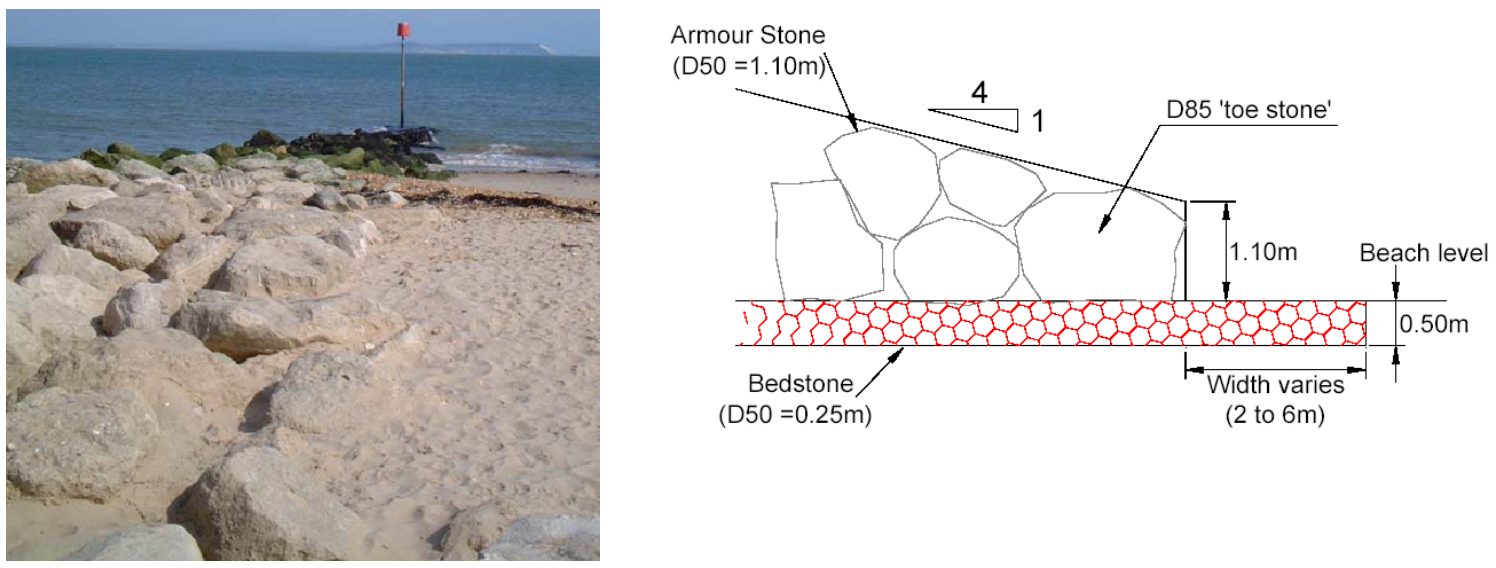

Simple groyne at the southern UK Coast, and toe detail [CROSSMAN ET AL., 2003]

In particular case in the southern UK, the use of a single armour grading with no under layer and the omission of a geotextile filter gave a saving of approximately $10 \%$ of the construction cost. Acceptance of regular minor damage enabled a smaller rock size, and consequently also a smaller rock volume. Of course, this all had lead to an increase in monitoring and maintenance costs. But all together the total savings, assuming a discount rate of $4 \%$ and a 50 year assessment period gave savings in the order of $25 \%$ of the total cost of the scheme. Playing with the damage factor in the stability formula for rock may reveal the optimum damage level. Sometimes a slightly thicker armour layer (e.g. 3 elements instead of 2) may reduce the size of the armour, and consequently also the total volume or rock required.

At the Bulgarian coastline, near Varna, some 15 years ago a number of breakwaters for marinas were constructed. Because of a number of reasons the Tetrapods used for this marinas were of very poor material quality; accidentally they were also slightly over dimensioned. At present no serious damage can be observed. This shows that in case of 
a robust design, not so much money has to be spent to top quality materials. Also here, one has to find for a good balance between costs and material quality.

\section{References}

BAGHELOE [1998] Breakwaters with a single layer. MSc Thesis, TU Delft, Hydraulic engineering Section

Crossman, M., Allsop, W., Segura Dominguez,S., Bradbury, A., A, Simm, J [2003] Economical rock groynes, Proc. Coastal Structures 2003, Portland, USA

CUI, J [2004] Experimental research of wave overtopping on a breakwater with concrete armour units. M.Sc.-thesis, TU Delft, Hydraulic Engineering Section.

DEJONG [2003] Experimental research on the stability of armour and secondary layer in a single layered Tetrapod breakwater. M.Sc.-thesis, TU Delft, Hydraulic Engineering Section.

Groot, M.B. De, Klein-Breteler, M, BezuiJen, A. [2003] Resultaten Geocontaineronderzoek (Results Geocontainer research), Delft Cluster Report DC1-321-11, (http://www.library.tudelft.nl/delftcluster/PDF-files/DC1-321-11.pdf)

Heilman, D.J., Hauske, G.J. [2003] Advances in geotextile tube technology, proc. Coastal Structures, 2003, Portland, USA

Klabbers, M, MutTray, M.O., ReEDIJK, J.S. [2003] Xbloc armour unit development: hydraulic performance of Xbloc armour units, 2D model tests at WL Delft, DMC report 210006-r-03, DMC, Gouda, The Netherlands

MELBY, J.A., TURK, G.F. [1997] CORE-LOC concrete armor units. Technical Report CHL-97-4, US Army Engineer Research and Development Center, Vicksburg, MS.

NiCOLON [1988] Nicolon products; Geosystems, Geotubes and Geocontainers. Company publication, TenCate/Nicolon, PO Box 236, Almelo, Netherlands.

PIANC-MARCOM [2004] Catalogue of prefabricated elements, Report of working group36, PIANC, Brussels (http://www.pianc-aipcn.org/).

PILARCZYK K.W. [2000] Geosynthetics and geosystems in hydraulic and coastal engineering Balkema, Rotterdam, ISBN 90.5809.302.6, 913 pp

Reedijk, M., Klabbers. M., VAnDenBerge, A., HaKenberg, R. [2003] Development of the Xbloc breakwater armour unit, $2^{\text {nd }}$ International conference on Port \& Maritime $\underline{R \& D \text { and Technology, Singapore }}$

TRIEMSTRA, R. [2000] The use of high density concrete in armour layers of breakwaters. M.Sc.-thesis, TU Delft, Hydraulic Engineering Section

TRIEMSTRA, R. [2001] Stability of high density concrete armour elements under wave attack PIANC bulletin 108

SPELT, K [2001] Geotubes as the Core of Guide Dams for Naviduct at Enkhuizen, The Netherlands Terra \& Aqua, nr 83 (IADC, The Hague, The Netherlands)

VAnDenBosch, A, D'Angremond, K, Verhagen, H.J., Olthof, J [2002] Influence of the density of placement of armour layers on breakwaters, proc . ICCE 2002, Cardiff, pp 1537-1549 
VanDerMeer, J.W. [2002] Technical Report wave run-up and overtopping at dikes, Technical Advisory Committee on Waterdefences, Delft, the Netherlands, $70 \mathrm{pp}$

VanGent M.R.A., SpaAn, G.B.H., Plate, S.E., Berendsen, E., VanDerMeer, J.W., D'ANGREMOND, K.[1999] Single-layer rubble mound breakwaters, proc. Int. Conf. Coastal Structures, Santander, Spain

VANGEnT, M.R.A.[2001] Wave run-up on dikes with shallow foreshores. J.of Waterway, Port, Coastal and Ocean Engineering, ASCE, vol.127 (5), pp 264-272

Verhagen, H.J., D'Angremond, K, VAnDerVliet, K. [2002] Positioning of cubes on a breakwater slope, proc. ICCE2002, Cardiff, pp 1550-1560

Weerakoon, S, Mocke, G.P., Smit, F., Al Zahed, K. [2003] Cost effective coastal protection works using sand filled geotextile containers. proc. Copede VI, Colombo, Sri Lanka 